\title{
AVALIAÇÃO MICROBIOLÓGICA DA ÁGUA DO ARROIO PESSEGUEIRINHO DE SANTA ROSA, NOROESTE DO ESTADO DO RIO GRANDE DO SUL
}

\author{
Bruna Gerardon Batista', Mateus Batista Fucks² \\ 1Biomédica, Pós-Graduanda em Análises Clínicas- IESA \\ Email: bruna batista@hotmail.com \\ ${ }^{2}$ Farmacêutico-Bioquímico, Pós-Graduado em Microbiologia- PUC/MG \\ Emil: mateus@labclinisul.com.br
}

\section{RESUMO}

O Arroio Pessegueirinho está em um estado de emergência devido ao alto índice de degradação ambiental proporcionado pela população que faz ligações da rede de esgoto diretamente no rio. As bactérias coliformes não causam doenças por habitar o intestino humano, mas a presença das bactérias coliformes na água de um rio significa que esse rio recebeu materiais fecais. A identificação de coliformes é feita facilmente, já que as bactérias pertencentes a esse grupo fermentam a lactose do meio de cultura, produzindo gases que são observados nos tubos de ensaio. Com o estudo, pode-se observar que o Arroio tem a qualidade de suas águas completamente comprometida, impróprias para o consumo humano ou animal, para banho ou para irrigação de frutas ou hortaliças, por apresentar uma concentração acima do permitido. As doenças de veiculação hídrica podem ser minimizadas mediante a adoção de práticas de saneamento como coleta e tratamento de esgotos domésticos e tratamento de águas de abastecimento. Desta forma, o tratamento e disposição dos esgotos seriam as mais importantes medidas para reverter essa situação de risco à saúde pública. Essas medidas, juntamente com um programa de educação sanitária, visariam o esclarecimento e a mudança de hábitos da população local.

Palavras-chaves: Arroio Pessegueirinho. Qualidade microbiológica da água. Coliformes totais. Coliformes fecais.

\begin{abstract}
The Pessegueirinho river is in a state of emergency due to the high environmental degradation index provided by the population which makes sewer network links directly into the River. Coliform bacteria do not cause disease by dwell the human gut, but the presence of coliform bacteria in water of a river means that this river received fecal material. The identification of coliforms is done easily, since bacteria belonging to this group will ferment the lactose of culture medium, producing gases that are observed in test tubes. The diseases can be minimized by adopting practices of sanitation as collection and treatment of domestic sewage treatment and water supply. In the study, we can observe that the River has the quality of its waters completely compromised, unfit for human or animal consumption, for swimming or for irrigation of fruit or vegetables, for presenting a concentration above the permitted. This way, the treatment and disposal of sewage would be the most important measures to reverse this situation of risk to public health. These measures, together with a program of health education, would aim the clarification and the changing habits of the local population.
\end{abstract}

Keywords: Pessegueirinho river. Water microbiology quality. Total coliforms. Fecal coliforms. 


\section{INTRODUÇÃO}

O Arroio Pessegueirinho, que atravessa o município de Santa Rosa-RS está a cada dia que passa em um estado de maior emergência, devido à degradação ambiental proporcionada pela população que faz ligações clandestinas da rede de esgoto diretamente no rio. (SEMA, 2011).

Esses dejetos que são depositados no rio acabam poluindo as águas com algumas bactérias que podem habitar os seres humanos como parte da biota normal como também podem contaminar a água com vários microrganismos patogênicos que irão ser transmitidos com um possível contato com essa água contaminada (ANVISA, 2000).

As bactérias coliformes não causam doenças, ao contrário, vivem no interior do intestino de todos nós, auxiliando a nossa digestão. A presença das bactérias coliformes na água de um rio significa que esse rio recebeu materiais fecais. Por outro lado, se a água recebe fezes, ela pode receber microrganismos patogênicos. Isso tem uma grande importância para a avaliação da qualidade da água dos rios: suas águas recebem esgotos, fatalmente receberão coliformes (OLIVEIRA, 2007).

O grupo dos coliformes fecais compreende o gênero Escherichia e, em menor extensão, espécies de Klebsiella, Citrobacter e Enterobacter. Algumas espécies são encontradas em águas ricas em matéria orgânica, efluentes industriais (por exemplo, Klebsiella pneumoniae) ou em material vegetal e solos em decomposição. Além disso, principalmente em climas tropicais, mesmo que originalmente introduzidas na água por poluição fecal, podem adaptar-se ao meio aquático. Portanto, a utilização dos coliformes fecais na avaliação da qualidade de águas naturais, principalmente em países de clima tropical, também tem sido questionada e a tendência atual é de se referir ao grupo como coliformes termotolerantes. Apesar disso e com base no fato de que entre os cerca de $10^{6}-10^{8}$ coliformes fecais $/ 100 \mathrm{~mL}$, usualmente presentes nos esgotos sanitários predomina a Escherichia coli (esta sim, uma bactéria de origem fecal), esses organismos ainda tem sido largamente utilizados como indicadores de poluição de águas naturais (SECRETARIA DE VIGILÂNCIA EM SAÚDE, 2006).

As bactérias do grupo coliforme são definidas na Portaria no 2.914/2011 como: coliformes totais, sendo representadas por bacilos gram-negativos do gênero Esherichia e coliformes termotolerantes, sendo representadas pela Escherichia coli, de origem exclusivamente fecal.

Esse artigo tem como objetivo realizar uma análise bacteriológica da água do arroio Pessegueirinho da cidade de Santa Rosa-RS para verificar a presença de coliformes totais e fecais em diferentes cursos.

\section{METODOLOGIA}

Foram coletadas seis amostras em diferentes cursos do Arroio Pessegueirinho, que podem ser localizadas conforme as setas indicativas da figura 1, com a posterior análise qualitativa e quantitativa quanto à presença de coliformes totais e fecais, através do método do Número Mais Provável (NMP).

As amostras foram coletadas e armazenadas em temperatura entre 2-8으, sendo analisadas no Laboratório Escola de Biomedicina do Instituto Cenecista de Santo Ângelo (IESA).

Foram coletados dois frascos estéreis de $100 \mathrm{~mL}$ de água para cada curso. As amostras foram analisadas de forma qualitativa e quantitativa quanto à presença de coliformes totais e 
fecais utilizando-se Caldo MUG Lauril Sulfato (Himedia). Em um dos frascos de cada curso foi adicionado o caldo desidratado para análise qualitativa. Para a análise quantitativa pelo método do número mais provável (NMP) cada amostra foi distribuída em 3 séries de 5 tubos, com diluição 1:1, 1:10 e 1:100 de amostra em relação ao caldo. Nos primeiros 5 tubos foram adicionados $10 \mathrm{ml}$ de água em uma diluição 1:1 do meio em concentração dupla. Nos próximos 5 tubos foram adicionados $1 \mathrm{ml}$ de água em diluição 1:10 em meio com concentração simples e nos últimos 5 tubos foram adicionados $0,1 \mathrm{~mL}$ de água em diluição 1:100 em meio com diluição simples. Após todos os frascos e tubos foram incubados por 24 horas em estufa bacteriológica a 35 으, para posterior leitura dos resultados.

O MUG é adicionado ao caldo como um composto fluorogênico, que permite a detecção rápida de Escherichia coli quando observada sob luz UV onde uma confirmação posterior não é necessária. A presença de coliformes totais é verificada pela alteração da cor amarelo claro para azul. A contaminação por Escherichia coli é confirmada utilizando-se uma lâmpada ultravioleta de $365 \mathrm{~nm}$ em ambiente escuro. A presença de fluorescência indica a hidrólise do MUG pela enzima beta-glucuronidase presente nesta espécie. Se a amostra permanecer com a cor amarelo claro após 24 horas de incubação o resultado é negativo, tanto para coliformes totais como para $E$. coli. O resultado foi expresso como presença ou ausência de coliformes totais e Escherichia coli em 100 $\mathrm{mL}$ de amostra, bem como de forma quantitativa pelo método NMP, seguindo as recomendações da FUNASA (2006).

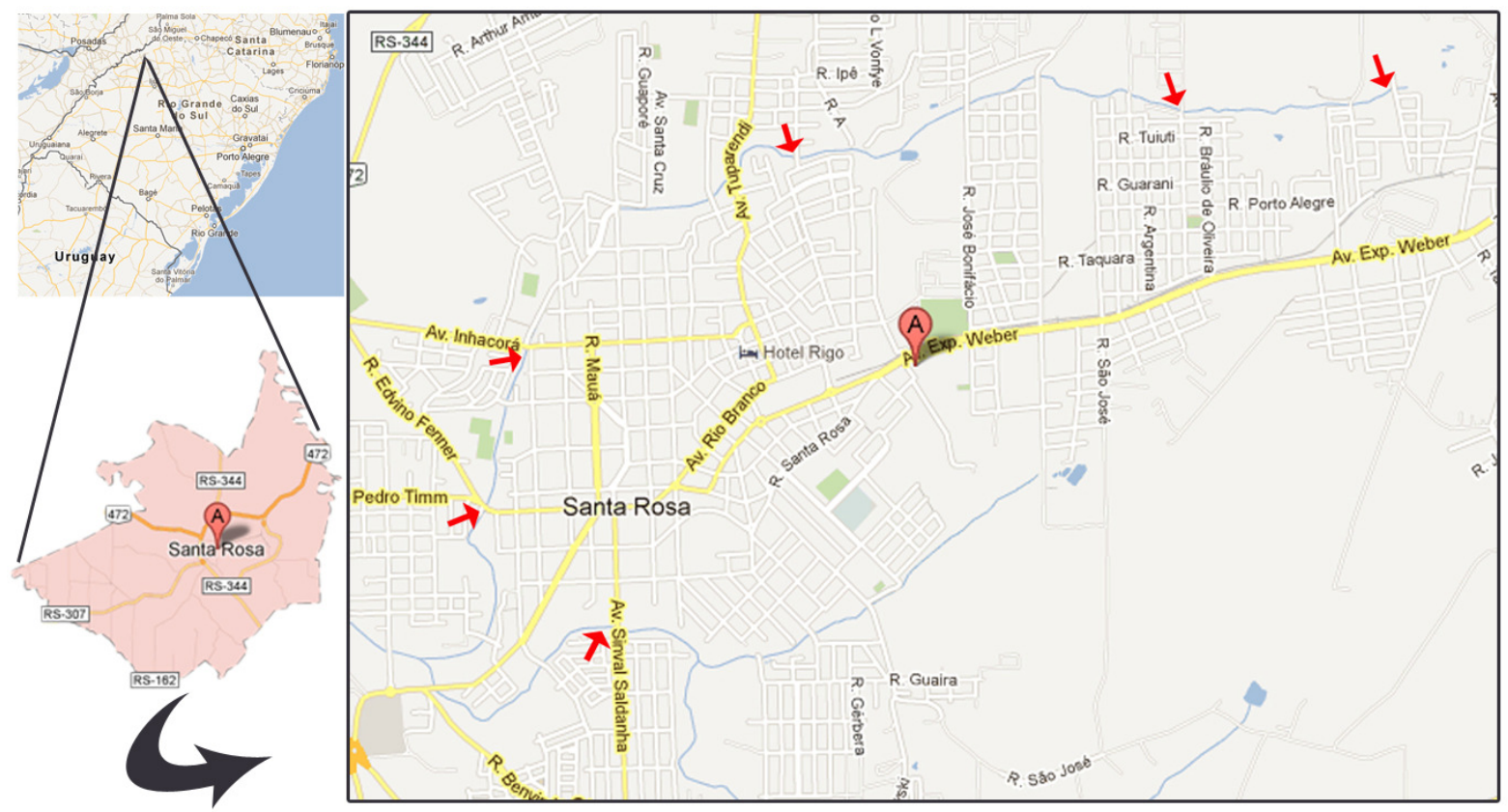

Figura 1. As setas vermelhas indicam os seis pontos onde foram realizadas as coletas do material.

\section{RESULTADOS E DISCUSSÃO}

Da análise dos resultados qualitativos verificou-se a presença de coliformes totais e fecais em todos os cursos do Arroio Pessegueirinho, conforme demonstra a figura 2. 


\begin{tabular}{c|c|c}
\hline Local da Coleta & Coliformes Totais & Escherichia coli \\
\hline Nascente Rio & Presença em $100 \mathrm{~mL}$ & Presença em 100mL \\
\hline Central & Presença em $100 \mathrm{~mL}$ & Presença em $100 \mathrm{~mL}$ \\
\hline Aliança & Presença em $100 \mathrm{~mL}$ & Presença em $100 \mathrm{~mL}$ \\
\hline Timbaúva & Presença em $100 \mathrm{~mL}$ & Presença em $100 \mathrm{~mL}$ \\
\hline Jardim Petrópolis & Presença em $100 \mathrm{~mL}$ & Presença em $100 \mathrm{~mL}$ \\
\hline Sulina & Presença em $100 \mathrm{~mL}$ & Presença em $100 \mathrm{~mL}$ \\
\hline
\end{tabular}

Figura 2. Resultado qualitativo

As principais fontes poluidoras que depositam dejetos diretamente no Arroio Pessegueirinho de Santa Rosa são empresas de alimentos que situam-se nas margens do rio e a população ribeirinha.

Com relação aos resultados quantitativos houve diferença apenas com relação a Escherichia coli na nascente do rio, que apresentou menor quantidade no crescimento bacteriano.

\begin{tabular}{c|c|c}
\hline Local da Coleta & $\begin{array}{c}\text { Coliformes Totais } \\
\text { (NMP/100mL) }\end{array}$ & $\begin{array}{c}\text { Escherichia coli } \\
\text { (NMP/100mL) }\end{array}$ \\
\hline Nascente Rio & $\geq 1.600$ & $\geq 1.600$ \\
\hline Central & $\geq 1.600$ & $\geq 1.600$ \\
\hline Aliança & $\geq 1.600$ & $\geq 1.600$ \\
\hline Timbaúva & $\geq 1.600$ & $\geq 1.600$ \\
\hline Jardim Petrópolis & $\geq 1.600$ & $\geq 1.600$ \\
\hline Sulina & $\geq 1.600$ & \\
\hline
\end{tabular}

Figura 3. Resultado quantitativo (NMP/100mL)

Na nascente do Arroio Pessegueirinho encontrou-se um crescimento de E. coli menor que nos demais cursos do rio pelo fato de nela possuir uma mata ciliar junto ao rio, que auxilia na proteção do mesmo e também por não possuir uma quantidade grande de casas na beira do mesmo. A localização da nascente, numa área mais afastada, dificulta o acesso da população, que muitas vezes não se desloca até a mesma para depositar lixo e dejetos, também é outro aspecto que contribuiu para a obtenção desse resultado. Mas vale ressaltar que este resultado não é significativo sob o ponto de vista da qualidade da água, o que torna o Arroio Pessegueirinho impróprio para banho e consumo de água desde sua nascente.

$\mathrm{O}$ fato de haver um crescimento bacteriano de coliformes fecais desde a nascente, porém em menor quantidade que nos demais cursos, ocorre pelo fato do Arroio possuir ligação de esgoto direta das casas legalizada pela prefeitura municipal. Esse fato ocorre pela região não poder sofrer perfurações intensas para instalações de foças sépticas devido ao solo ser muito úmido. 


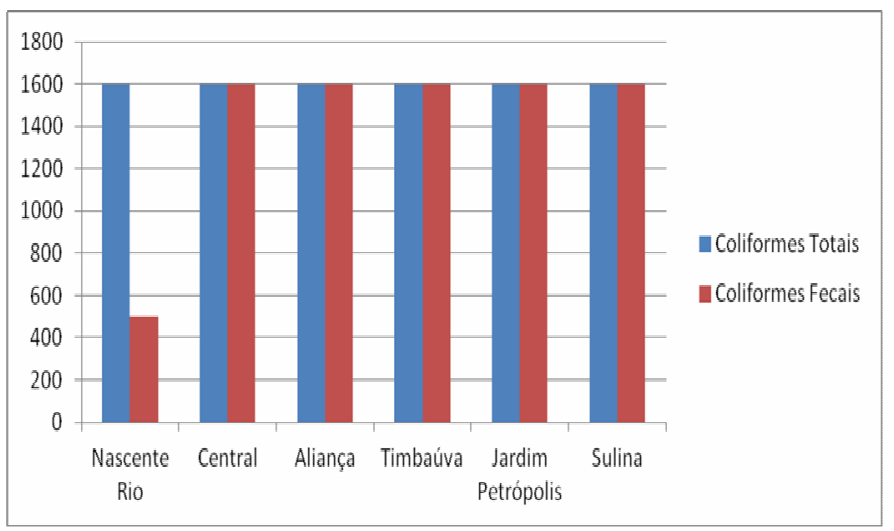

Figura 4. Resultado quantitativo NMP/100mL

Com exceção da nascente, nos demais cursos do rio, o número de coliformes fecais encontrados pelo método no NMP foi a máxima dentro de sua sensibilidade.

Em estudo semelhante realizado no Rio Jacu Braço Sul- ES (TERRA et. al., 2008), encontraram-se variações ao longo do período de monitoramento em relação a concentrações de coliformes termotolerantes. Com exceção de dois pontos, todos os demais analisados foram encontrados indícios de contaminação, porém, todos os valores observados estão dentro do limite estabelecidos pelo CONAMA (1.000 coliformes termotolerantes por $100 \mathrm{~mL}$ ), referente à proteção à vida aquática e à recreação de contato primário, sendo esse achado impróprio para o consumo humano. As amostras analisadas do Arroio Pessegueirinho de Santa Rosa-RS apresentaram uma contaminação superior a 1.600 coliformes por $100 \mathrm{~mL}$ de água, valor acima do estabelecido pelo CONAMA, o que nos garante que há uma contaminação muito maior nas águas do Arroio analisado no presente estudo.

Em outro estudo realizado em águas do Rio São Lourenço- RS (VASCONCELOS et. al., 2006), 80 \% dos pontos de coletas analisados, apresentaram segundo a Resolução $n^{\circ} 357$ do CONAMA (17/03/2005), águas impróprias para o consumo humano ou animal. Comparando o resultado com os obtidos no presente estudo, podemos observar que os rios estão recebendo contaminação fecal em suas águas em todos os seus cursos, o que aumenta cada vez mais os riscos para a saúde da população que tem suas residências nas margens desses rios. Como o Rio São Lourenço é utilizado para a navegação, banho e irrigação, os resultados da contaminação são mais influentes para a população que pode vir a ter um contato com essa água, visto que suas águas desembocam na Laguna dos Patos- RS, recebendo também ao longo de seu percurso resíduos agrícolas e efluentes domésticos sem tratamento prévio, agravando ainda mais a situação desse rio.

Já no Rio Itanhém, localizado em Teixeira de Freitas- BA, CUNHA et. al., 2010 constatou uma diferença na presença de coliformes termotolerantes ao longo dos trechos observados, passando a apresentar um aumento de não contaminado para $50 \%$ onde o rio recebeu uma parcela de efluentes e $66,6 \%$ na medida em que esse rio passou a receber esgotos domésticos, agrícolas e industriais. Estatísticas diferentes do Arroio Pessegueirinho, que mesmo na nascente onde não deveria existir contaminação, apresentou presença de coliformes. 
MORELLI e colaboradores analisaram o Rio Lageado Acelo, situado em Cascavel- PR, cujas águas são diariamente utilizadas por crianças para lazer e banho e confirmaram a positividade dos testes para coliformes totais e termotolerantes. Esses resultados tornam o rio impróprio para esse tipo de atividade que as crianças vêm realizando no mesmo, porém, os números registrados ainda são menores que os encontrados no Arroio Pessegueirinho, o que indica que o Arroio de Santa Rosa- RS encontra-se em um nível de degradação ambiental que merece cuidados e atenção especial por parte da população assim como também por órgãos ambientais responsáveis.

Cunha et. al., 2004, encontrou uma contaminação em rios urbanos do Amapá, porém, correlacionou o achado como uma "mão dupla de movimento" por acreditar que as forças de marés e precipitações pluviométricas contribuíram para o elevado nível de coliformes fecais encontrados nas águas aparentemente saudáveis a olho nu. Acredita-se que o Arroio Pessegueirinho não apresentou viés com os resultados obtidos pelas coletas terem sido realizadas em um período em que havia uma estabilidade em relação à chuva e temperatura, impossibilitando então, precipitações pluviométricas.

\section{CONCLUSÃO}

O monitoramento periódico da qualidade microbiológica da água e a observação das medidas de proteção contra o contato direto com possíveis águas contaminadas são fatores importantes para a prevenção de doenças de veiculação hídrica. A concentração de coliformes termotolerantes foi utilizada como indicador de poluição, pelo efeito do lançamento de esgotos e resíduos domésticos e industriais sem tratamento no curso do Arroio Pessegueirinho. Assim, considera-se que o Arroio tem a qualidade de suas águas completamente comprometida, impróprias para o consumo humano ou animal, para banho ou para irrigação de frutas ou hortaliças, por apresentar uma concentração acima do permitido (>1.000/100 mL). Desta forma, o tratamento e disposição dos esgotos seriam as mais importantes medidas para reverter essa situação de risco à saúde pública. Por fim, a partir desses dados, é perceptível a necessidade de políticas públicas que viabilizem a conservação dos recursos hídricos da região.

\section{REFERÊNCIAS BIBLIOGRÁFICAS}

ANVISA. Agência Nacional de Vigilância em Saúde. Manual de Microbiologia Clínica para o Controle de Infecção em Serviço de Saúde. Editora Agência Nacional de Vigilância Sanitária, ed.1. Brasília, 2000.

BRASIL. Fundação Nacional de Saúde (FUNASA). Manual Prático de Análise de Água. Fundação Nacional de Saúde, ed.2. Brasília, 2006.

BRASIL. Ministério da Saúde. Secretaria de Vigilância em Saúde. Vigilância e Controle da Qualidade da Água para Consumo Humano. Brasília: Ministério da Saúde, 2006. 
CESAN. Companhia Espírito Santense de Saneamento: Portaria: 2.914 do Ministério da Saúde. Espírito Santo, 2011.

CONSELHO NACIONAL DO MEIO AMBIENTE. Resolução CONAMA no 357/2005. A classificação dos corpos d'água e diretrizes ambientais para o seu enquadramento. Brasília: Ministério do Meio Ambiente, 2005.

OLIVEIRA, Lia. A importância da vigilância da qualidade d água no município de São Gonçalo. Rio de Janeiro, 2007.

TERRA, V.; SANTOS, R.; ALIPRANDI, R.; BARCELOS, F.; AZEVEDO, R.; BARBIÉRI, R. Avaliação Microbiológica das Águas Superficiais do Rio Jacu Braço Sul, ES, Brasil. Natureza on line, v.6, p.48-52. 2008.

VASCONCELLOS, F., IGANCI, J.; RIBEIRO, G. Qualidade Microbiológica da Água do Rio São Lourenço, São Lourenço do Sul, Rio Grande do Sul. Arquivos do Instituto de Biologia Vegetal, v.73, n.2, p.177-181. São Paulo, 2006.

CUNHA, A.; TARTLER, N.; SANTOS, R.; FORTUNA, J. Análise Microbiológica da Água do Rio Itanhém em Teixeira de Freitas- BA. Revista Biociências, v.16, n.2. São Paulo, 2010.

MORELLI, M.; ALMEIDA, M.; TURECK, S. Análise Microbiológica da Água do Rio Lageado Acelo, Cascavel, Paraná, Brasil. Revista Brasileira de Biociências, v.6, supl.1, p.57-58. Porto Alegre, 2008.

CUNHA, A.; CUNHA, H.; JÚNIOR, A.; DANIEL, L.; SCHULZ, H. Qualidade Microbiológica da Água em Rios de Áreas Urbanas e Periurbanas no Baixo Amazonas: o Caso do Amapá. Revista Engenharia Sanitária Ambiental, v.9, n.4, p.322-328. Rio e Janeiro, 2004. 